\title{
VARIA
}

\section{DOS NUEVOS MORALES Y OBRAS DE EPÍGONOS DEL PINTOR: BENITO SÁNCHEZ GALINDO Y EL MAESTRO DE LA MAGDALENA DE LILLE (FRANCIA)}

Dos temas muy abundantes en la obra de Morales y la de su taller fueron la Piedad y el Ecce Homo. Rodríguez G. de Ceballos ha tratado de justificar esta presencia a través de la complicada y «crispada» vida religiosa española de la segunda mitad del siglo xv, por la influencia de Trento y, además, por una literatura que giraba alrededor de los temas pasionarios ${ }^{1}$.

Al extenso catálogo de Luis de Morales con el tema del Ecce Homo, que respondía a la demanda de una clientela numerosa, y que dio lugar a la creación de un taller de calidades notables, sumamos hoy dos nuevas tablas, de diferente calidad, pero, también, en muy distinto estado de conservación. La primera es una excelente interpretación del tema, pintada con pulcra minuciosidad, en la que Cristo aparece de busto, coronado de espinas y sujetando la caña dada por lo sayones, y con ensangrentada cabeza después de la coronación como rey de los judíos (fig. 1). Se halla en colección privada madrileña procedente, primero, del oratorio del palacio de Miraflores, situado en la Carrera de San Jerónimo, de Madrid, cuyo dueño era don Manuel Pando y Merino, presidente y ministro de Isabel II. Por línea directa pasó después a don José Álvarez de Toledo, Conde de Villapaterna y de él a los actuales propietarios. El modelo tiene mucho en común con otro Ecce Homo de la antigua colección Adanero, incluso en el detalle de cubrir a medias con el cabello la oreja de Cristo ${ }^{2}$.

El otro Ecce Homo que hoy damos a conocer, se halla en colección privada de Barcelona (fig. 2). El modelo de composición es similar al de la colección madrileña de don Julio Bobo ${ }^{3}$, coincidiendo ambos en el modelo de cabeza, cabellera, barba, y postura del cuerpo, pero prescindiendo la versión catalana de la soga al cuello, que sí aparece en el de la madrileña. El tratamiento en esta última versión, es más delicado, pero queremos insistir en el mal estado de conservación - como puede apreciarse por la fotografía - donde la pintura no sólo se ve barrida sino saltada. Por ello, no nos atrevemos a darla - a pesar de la calidad - como obra de Morales, sino que habría que considerarla como una tabla excelente del taller.

Precisamente en el taller de Morales ha incluido don Carmelo Solís a un pintor extremeño, Benito Sánchez Galindo, al que con dudas atribuye la tabla de San Benito enseñando a sus monjes (fig. 3), del monasterio de Montserrat ${ }^{4}$.

\footnotetext{
' A. Rodríguez G. de Ceballos: El mundo espiritual de Luis de Morales en el IV Centenario de su muerte, Goya, 1987.

${ }^{2}$ Reproducido el de Adanero en I. Bäcksbacka, Luis de Morales. Helsinki, 1962. Cat. N. ${ }^{\circ}$ A21, donde aparece como obra dudosa. El de la colección madrileña que hoy damos a conocer mide, $47 \times 30 \mathrm{cms}$.

${ }^{3}$ C. Solís Rodríguez, Luis de Morales. Badajoz, 1999. Catálogo, nº 37, pp. 230-231.

${ }^{4}$ Loc. cit. nota 3, pp. 98-99.
} 


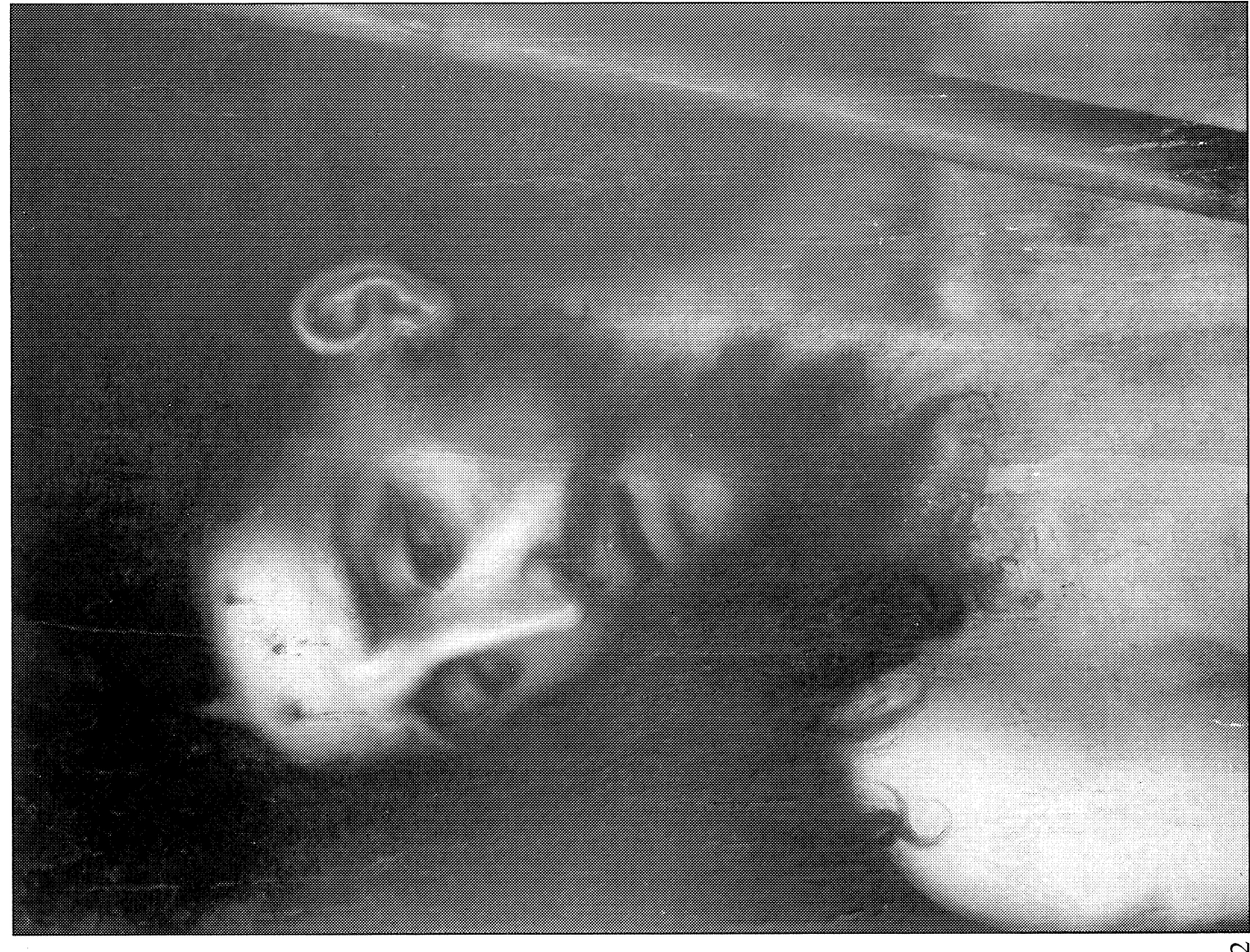

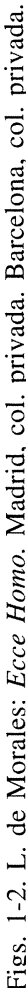

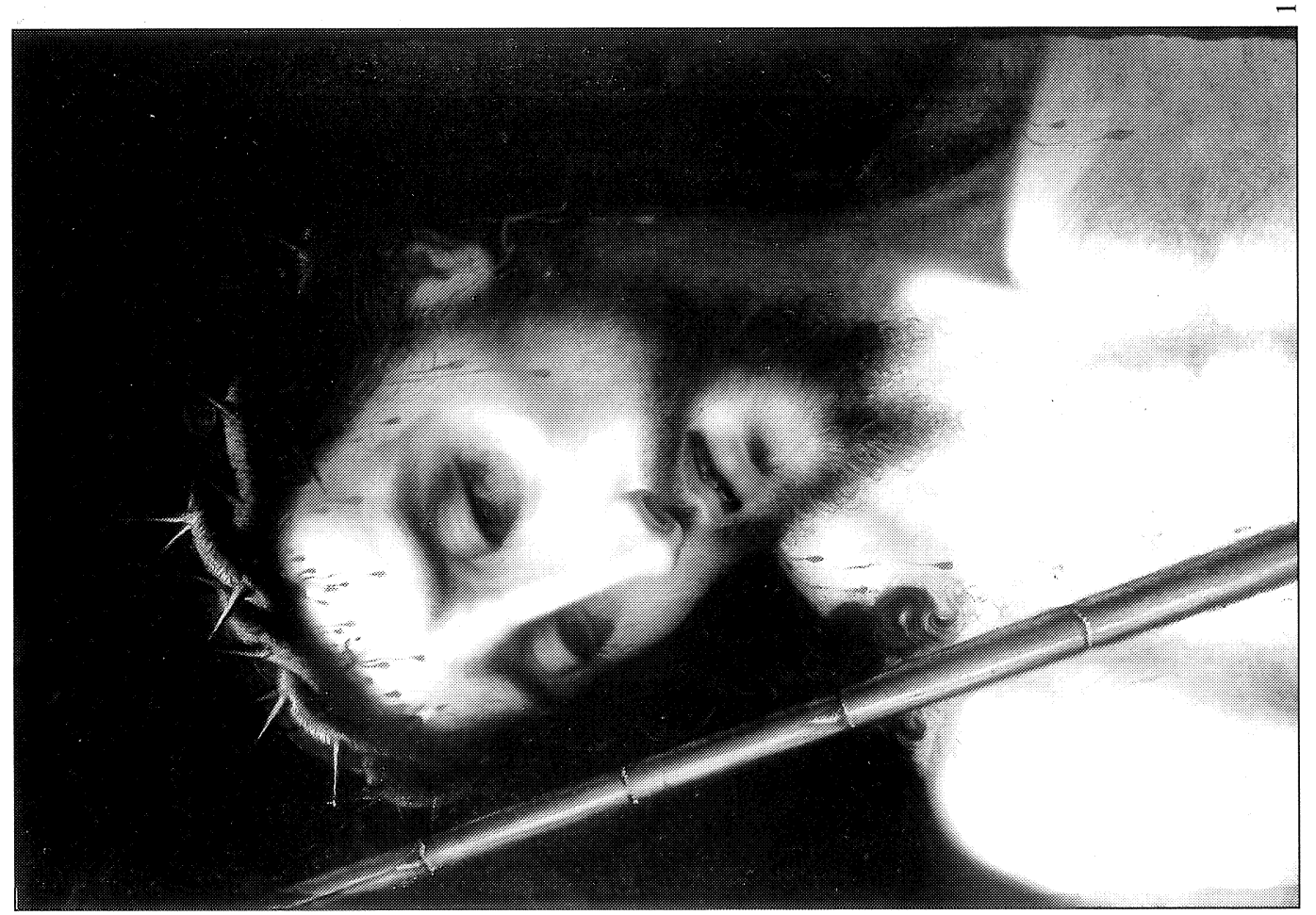

AEA, LXXVI, 2003, 303, pp. 301 a 329 
Desde hace años tenía apartadas dos tablas que, revisando el fichero de Recuperación, me habían parecido de la misma mano y de un pintor sugerente por sus características ${ }^{5}$. Por el formato debían proceder del banco de un retablo y por el lugar donde las depositaron durante la guerra, debían de proceder de alguna colección privada. Una de ellas representa a San Benito y San Sebastián (fig. 4), repitiendo modelo y actitud el primer santo, con el protagonista de la tabla de Montserrat. En la otra se representa a San Juan Evangelista (fig. 5), que tal vez, originariamente, iría acompañado por otro santo.

En el citado libro de don Carmelo Solís ${ }^{6}$, en el capítulo dedicado a los discípulos y epígonos de Morales, cita la tabla de un banco con Santiago y San Mateo (fig. 6), que Bäcksbacka publicó en su día como San José con el Niño, entre las obras dudosas de Morales ${ }^{7}$. Don Carmelo Solís no puso en relación estilística esta tabla con la de Montserrat, considerándola como procedente del banco del retablo de la Capilla de Santa Ana, en la catedral de Badajoz, que fue desmantelado en 1844 por don Diego de Carvajal patrono de la Capilla. Las tablas se hallan repartidas en la actualidad entre sus herederos, entre los que se encuentra el marqués de Camarena y doña Carmen Casillas Trespalacios, localizándose la tabla que comentamos, en la actualidad, en la colección privada de uno de los herederos del primero. También considera Solís, que en el retablo, además de Morales, debió pintar otro maestro, sugiriendo nombres como los de Francisco Flores, Francisco de Hermosa, Francisco Hernández, Solano, etc., como posibles colaboradores, ya que trabajaron para la catedral ${ }^{8}$.

No sabemos de donde deduce Solís la participación de Morales en el retablo de la Capilla de Santa Ana, desde luego de las tablas del banco es imposible deducirlo. Nos parece más factible que el retablo sea obra de Sánchez Galindo y que a él pertenezcan las tablas halladas en Recuperación y tal vez otras dos de las que trataremos a continuación.

En primer lugar le atribuimos y pensamos que procede del mismo retablo, una Misa de San Gregorio (fig. 7), que se hallaba en la colección Montenegro, de Cáceres, en $1950^{9}$, y que coincide en modelos con todo lo visto anteriormente de Sánchez Galindo. Lo mismo ocurre con un Bautismo de Cristo (fig. 8), publicado por Bäksbacka como obra dudosa de Morales ${ }^{10}$, entonces en la colección de la citada marquesa de Camarena, y que recientemente ha sido vendida como obra valenciana del círculo de Felipe Pablo de San Leocadio ${ }^{11}$. En ella, el modelo de Cristo coincide con los de San Benito, y el de San Juan Bautista, es exactamente igual al de San Mateo del banco del retablo de Badajoz.

¿Quién era Benito Sánchez Galindo y donde podríamos enclavar su estilo? Al parecer era miembro de una familia de gramáticos al servicio de la catedral de Badajoz, alternando al mismo tiempo su faceta de pintor con la de literato. Don Carmelo Solís, que es el que más líneas le ha dedicado hasta el momento, basándose en que cuando tiene lugar el proceso de Puebla de la Calzada, Sánchez Galindo declara tener diecinueve años, sitúa como fecha de su nacimiento en torno al año 1530, sugiriendo que, tras sus años iniciales en Badajoz, se trasladó a Barcelona donde aparece entre 1562 y 1589 , escribiendo allí su Christi Victoria, en $1572{ }^{12}$.

\footnotetext{
${ }^{5}$ Fichero de Recuperación. Museo del Prado, n. ${ }^{\circ} 1935$ y 3347. Dpto. de Historia del Arte del C.S.I.C.

${ }^{6}$ Loc. cit. nota 3 .

${ }^{7}$ I. Bäcksbacka, Luis de Morales. Helsinki, 1962, fig. 3, p. 184.

${ }^{8}$ Loc. cit. nota 3, pp. 408-413. Junto a la tabla de Santiago y San Mateo considera también del banco del retablo a una Santa Catalina y Santa Lucía, que considera de Morales o su círculo, pero que nada tienen que ver estilísticamente con la otra tabla de Santiago y San Mateo.

${ }^{9}$ Localizada en el Archivo Amatller de Barcelona con el n. ${ }^{\circ}$ G. 21134.

${ }^{10}$ Loc. cit. nota 7, fig. 2, p. 184.

"Catálogo Alcalá Subastas, del 20 de junio del 2001, n. ${ }^{\circ} 75$. Óleo sobre tabla, $98 \times 81,5 \mathrm{cms}$.

${ }^{12}$ Loc. cit. nota 3, pp. 98-99. Idem, «Los Galindo una familia de gramáticos y artistas extremeños del siglo xvı en Badajoz», en Actas del XII Congreso Nacional de Archiveros Eclesiásticos. León, 1996. Oviedo, 1997, pp. 459-483.
}

AEA, LXXVI, 2003, 303, pp. 301 a 329 

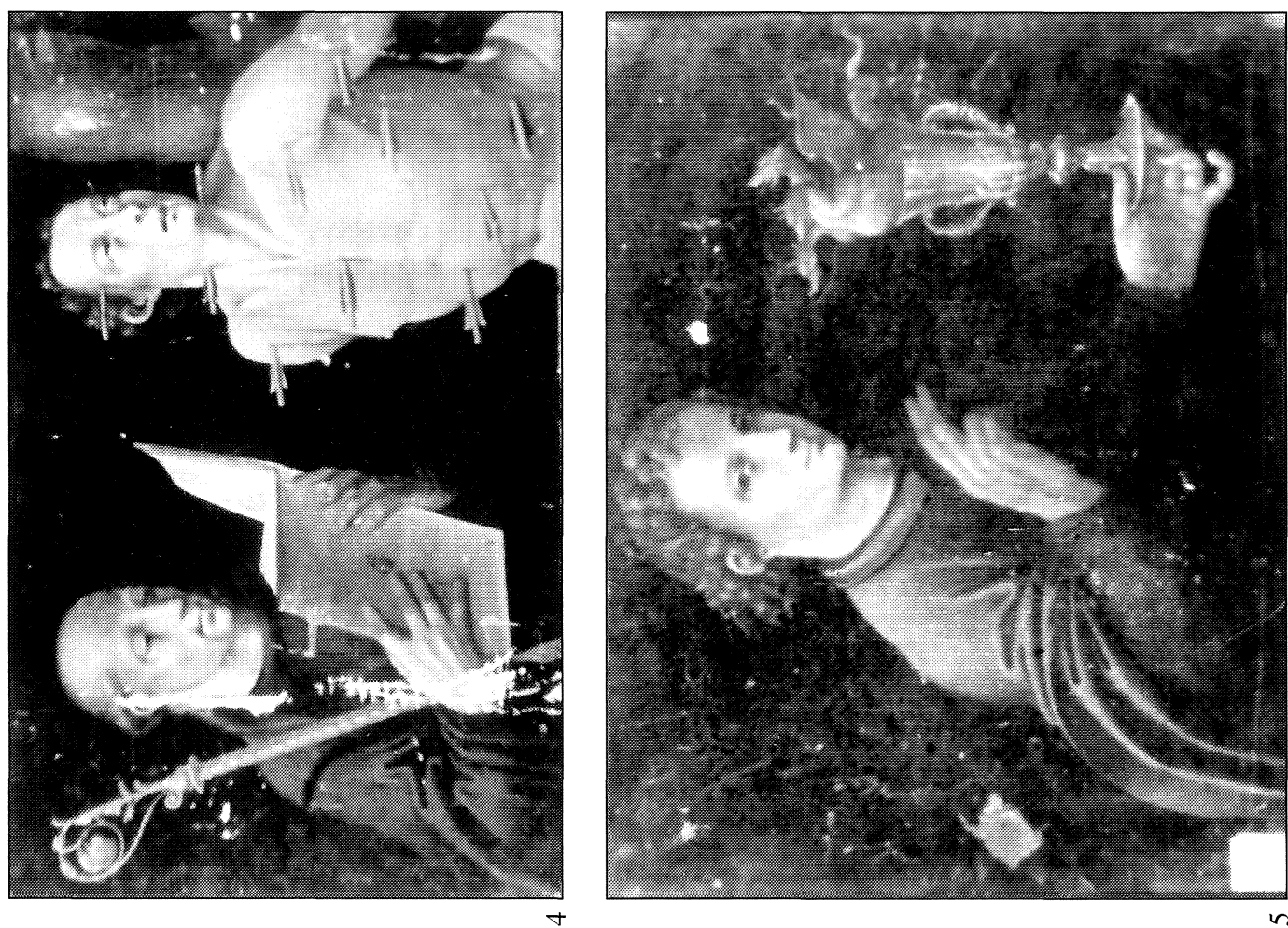

要,

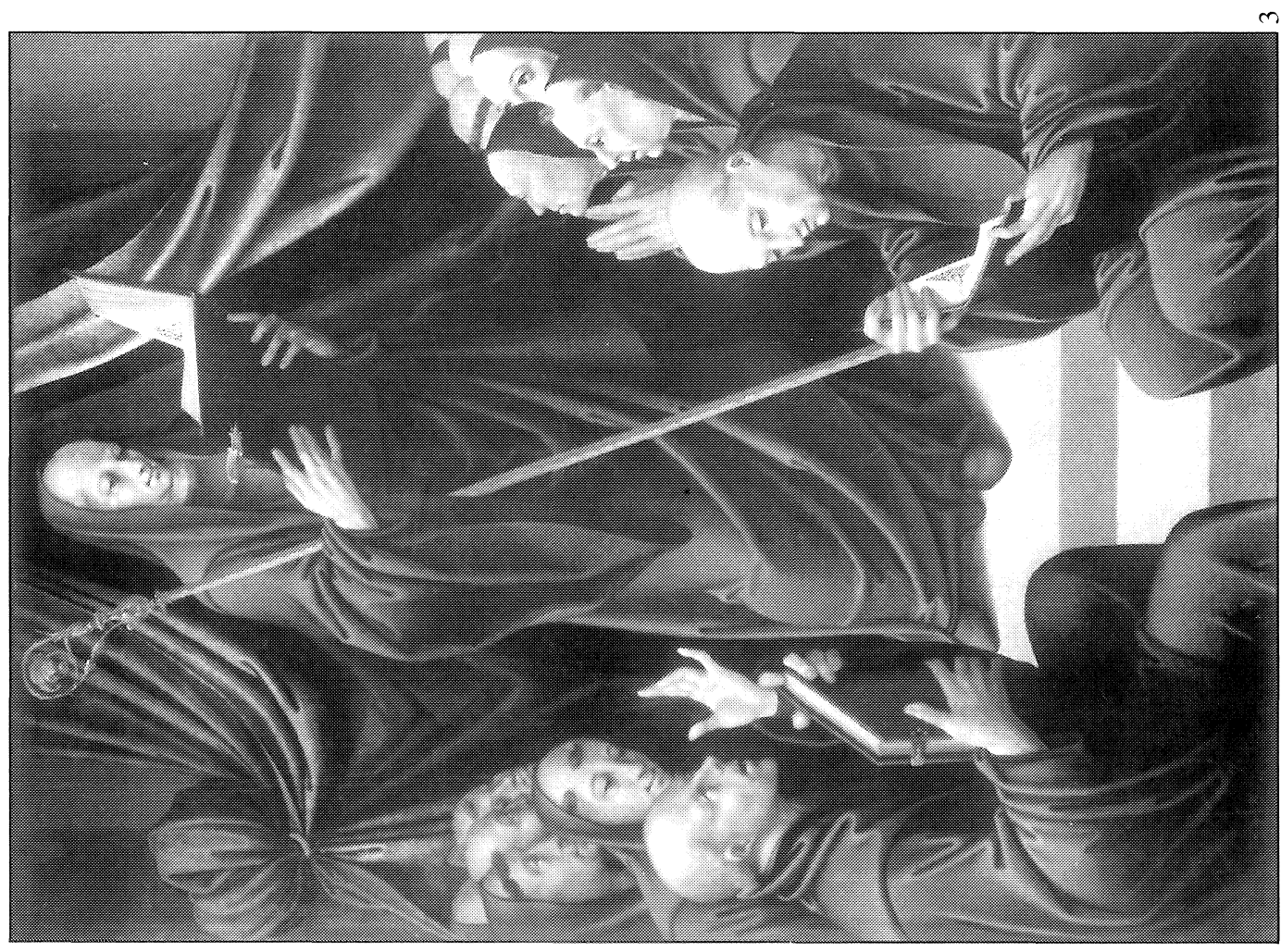

m

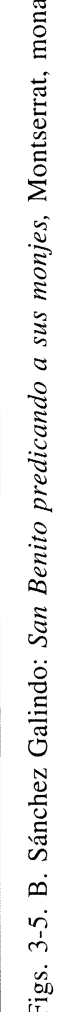

AEA, LXXVI, 2003, 303, pp. 301 a 329 


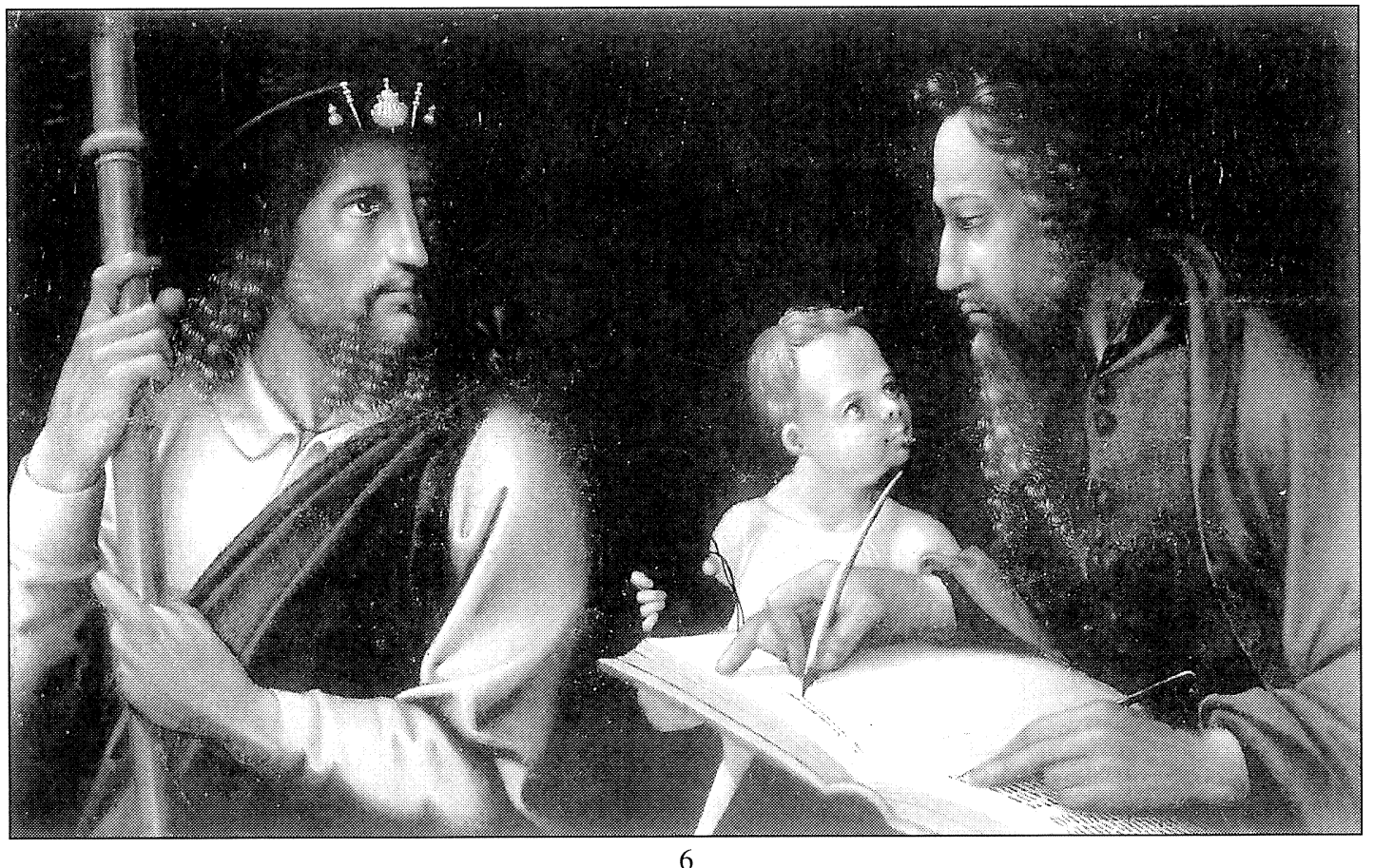

7

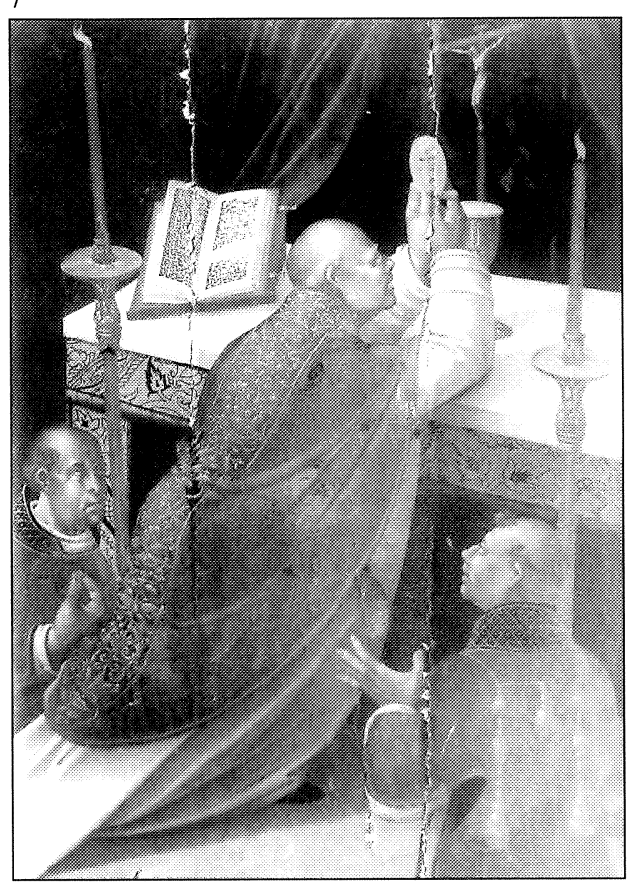

Fig. 6-8. B. Sánchez Galindo: Santiago y San Mateo, Cáceres, Col. herederos del Marqués de Camarena. Misa de San Gregorio, Cáceres, Col. Montenegro. Bautismo de Cristo, en comercio madrileño (año 2001).

AEA, LXXVI, 2003, 303, pp. 301 a 329

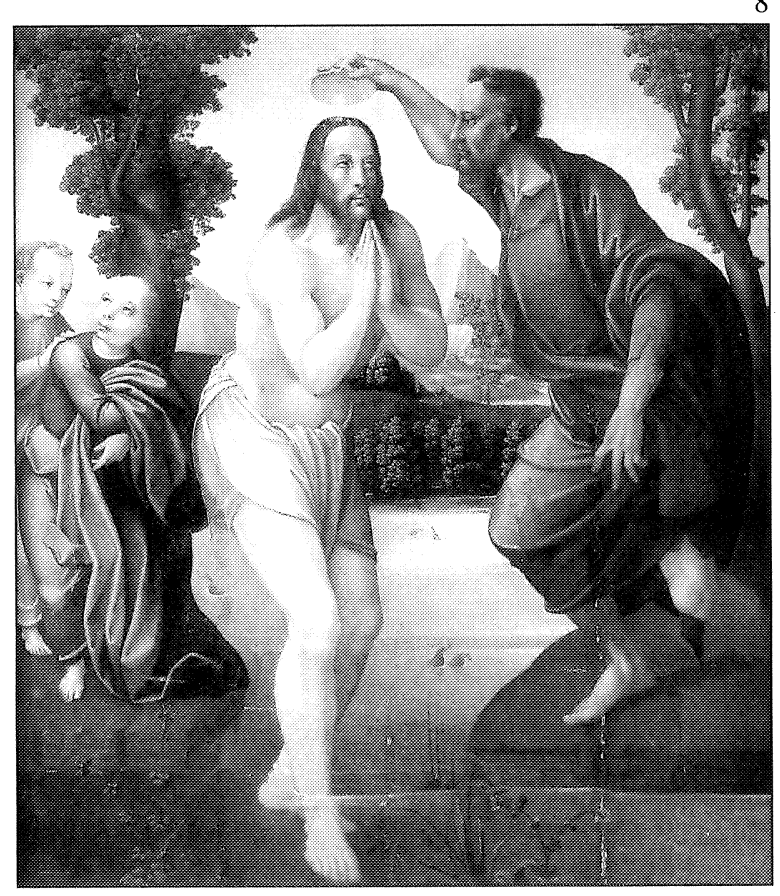


En el trabajo de Camacho Macías, se recogen datos de diferentes autores sobre Sánchez Galindo, destacando el Ensayo de José Gallardo, escrito en 1888, en el que se reproducía la portada de la Christi Victoria, en la que se alude al oficio de pintor, del autor de la obra: «Octava rima, por Benito Sanchez Galindo pintor extremeño y ciudadano de Barcelona». De otro autor, Viu, recoge la noticia de que Sánchez Galindo era oriundo de Romangordo, criticando a Nicolás Díaz y Pérez, de cambiar el nombre de esta localidad por la de Romancorbo, y de que sitúe a Sánchez Galindo en el siglo XVII. También censura la nota recogida por Nicolás de Antonio, por imprecisa, citando mal el título de la obra literaria de Sánchez Galindo. Respecto al interés que mostró Rodríguez Moñino por Sánchez Galindo como escritor, dice que éste buscó con ahínco el único ejemplar de la Christi Victoria, sin encontrarlo, conformándose con las noticias aportadas por Gallardo, que fue el que sin duda lo vio. Rodríguez Moñino localizó otras obras literarias de Sánchez Galindo, planteando la duda de si podría ser natural del mismo Badajoz, tesis mantenida por Carmelo Solís y a la que se opone Camacho García aduciendo que en ningún lugar Sánchez Galindo dice que sea de Badajoz, sino pintor vecino de esa ciudad ${ }^{13}$.

No cabe duda de que es importante para perfilar en lo posible la figura de Benito Sánchez Galindo como pintor, las declaraciones que él mismo hizo al respecto y que aparecen recogidas en el prólogo y dedicatorias de la Christi Victoria. Recordemos que Gallardo aportó los datos de que era pintor y vecino de Barcelona, sacados del prólogo, datos que han venido repitiéndose. Sin embargo, hoy podemos sumar a estas noticias la localización del único ejemplar existente de la Christi Victoria, en la Biblioteca Pública Lambert Mata, de Ripoll (Gerona), en cuya portada de la obra aparece el escudo de don Diego de Córdoba, duque de Cardona y de Segorbe, marqués de Comares, a quien Sánchez Galindo dedica la Victoria Christi ${ }^{14}$. Los dos primeros títulos le vienen por su matrimonio con doña Juana de Aragón Folch de Cardona, quinta duquesa de Cardona y cuarta de Segorbe, y el marquesado por una rama de los Fernández de Córdoba. Fue también noveno Alcaide de los Donceles, y se le conoció por Diego de África o el «Africano», por haber nacido en Orán.

Volviendo a la portada del libro, sobre el escudo, y antes de pasar a explicar la intención y contenido de la obra, lo que Benito Sánchez Galindo declara es, simplemente, que es pintor extremeño y ciudadano de Barcelona. Más adelante, en la dedicatoria dirigida al rey [Felipe II], de Castilla y Aragón y Conde de Barcelona, firmada por el Prior don Fernando, éste vuelve a presentar a Sánchez Galindo como pintor y vecino de Barcelona. Pero son los sonetos del propio Galindo, dedicados a los lectores, donde mejor se define su doble faceta como pintor y literato:

Entre los ratos que he hurtado al sueño

y a mis colores tablas y pinzeles

trace lector amigo en mis papeles

de nuestra redempción algun disetio

Esta alternancia entre literatura y pintura podría haber justificado el que su obra no hubiera sido pródiga en ninguna de las dos facetas. No obstante, el Diccionario biográfico de Artistas de Cataluña (Barcelona, 1964), lo incluye como pintor de origen castellano citando una larga lista de obras suyas, documentadas entre 1562 y 1589, algunas de especial significación para el arte catalán. Rodríguez Moñino, en «Los Pintores badajoceños del siglo XVI», en Revista de Estudios Extremeños, 1955, recoge el texto completo por el que se sabe que en 1562 pintó la bandera del Cabildo de la Seo vicense; en 1563 contrató la pintura de un retablo para el

13 «Personajes en la Historia: Benito Sánchez Galindo», Rev. Alminar, marzo 1981, p. 2.

${ }^{14}$ Agradezco a doña Concepción Canadell, directora de la Biblioteca y a mi buen amigo y compañero Jesús García Añoveros su ayuda para la consulta de este libro.

AEA, LXXVI, 2003, 303, pp. 301 a 329 


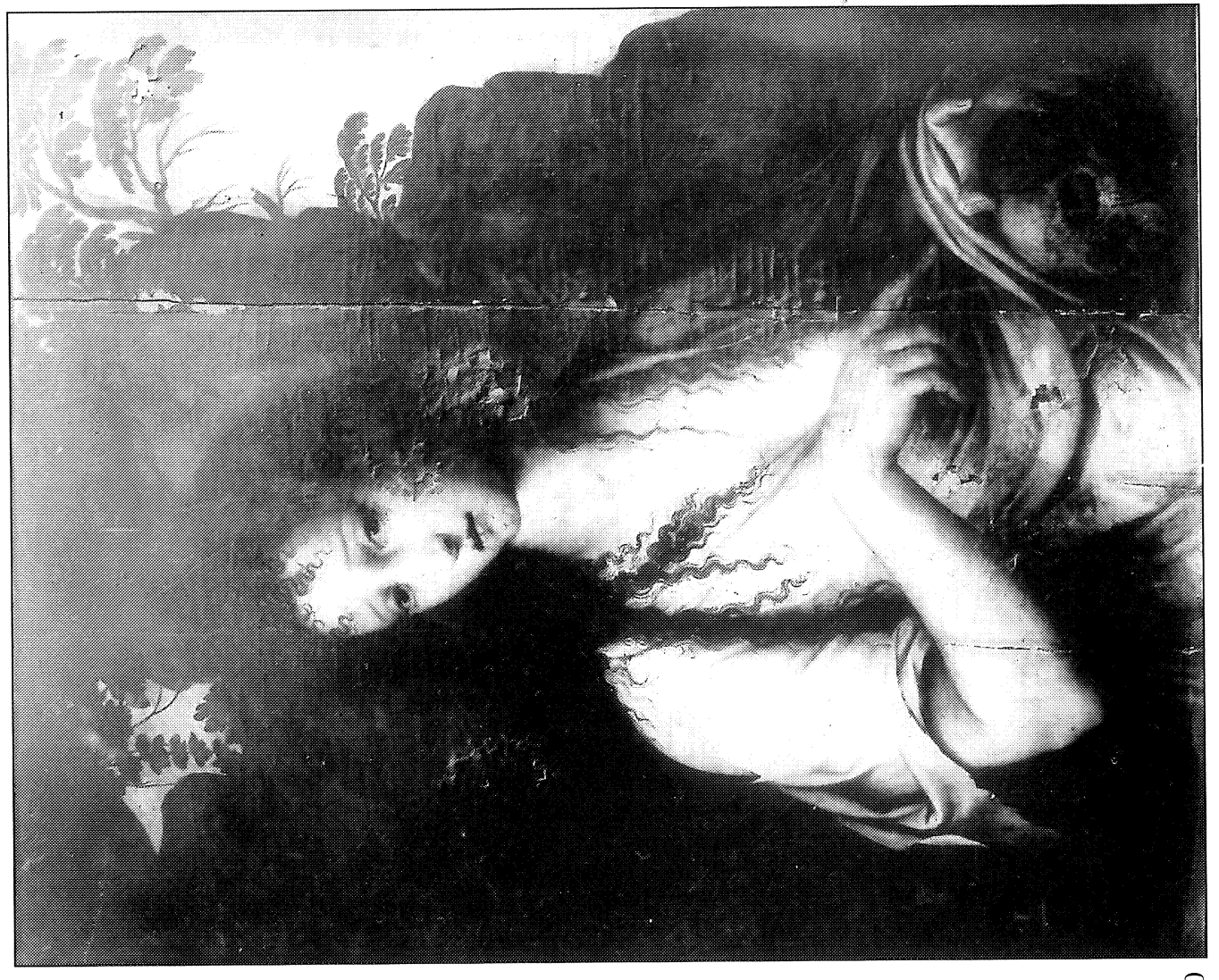

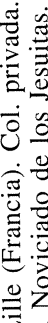

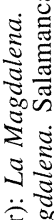

a

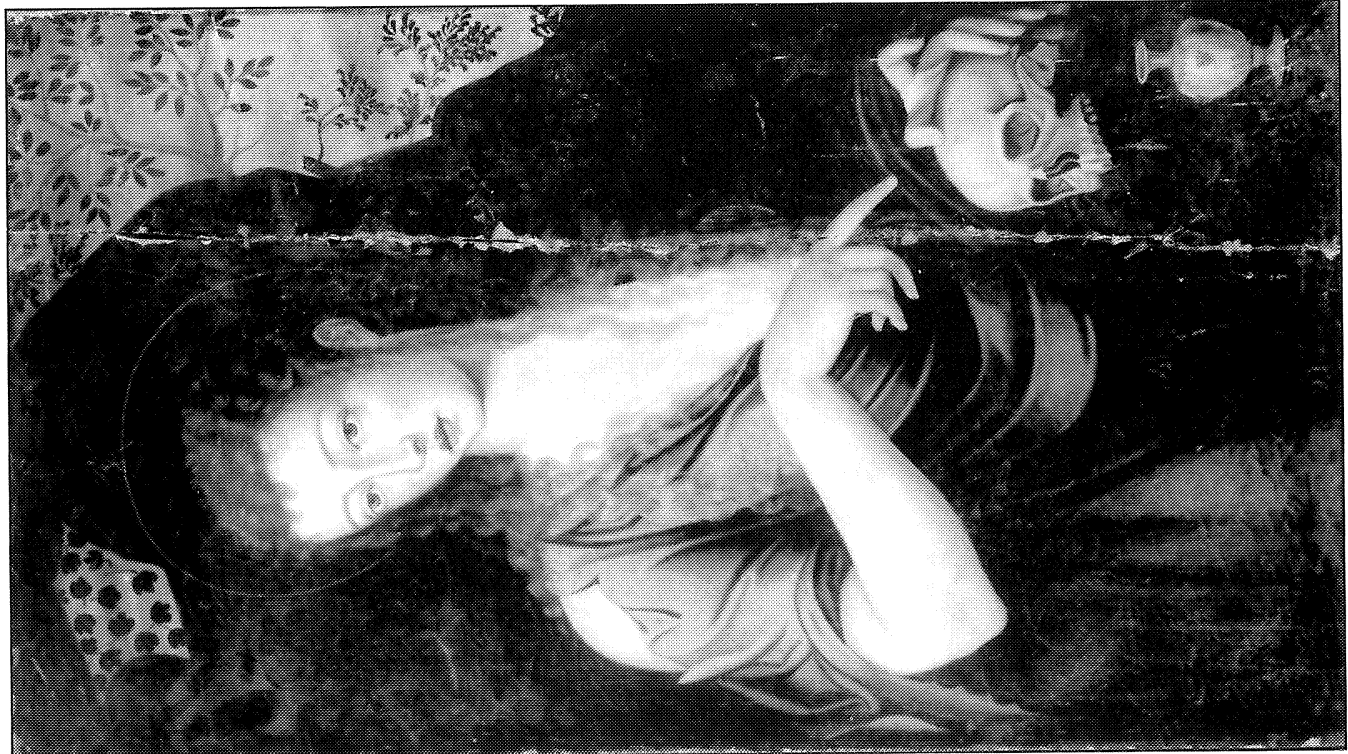

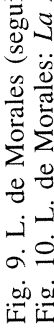

AEA, LXXVI, 2003, 303, pp. 301 a 329 
monasterio de San Benito de Bagés; en 1569 otro para la Cofradía del Santo Espíritu de Manresa, que debía instalarse en la Capilla de San Poncio; en 1570 firma las condiciones de un retablo para la parroquia de Santa María del Serrateix; en 1575 pintó diecisiete cuadros para la Sala de la «Colació» del Monasterio de Montserrat (fig. 3); en 1581 en compañía del pintor Antonio Toreno, contrata la pintura de la bandera de Santa Eulalia, por encargo de los «consellers», de Barcelona; en 1588 cobra por la pintura y dorado de la Galera Capitana de la escuadra imperial. También consta que tuvo mucha relación con el toledano Isaac de Hermés.

En nuestra búsqueda por guías y catálogos de los lugares reseñados y en el Archivo Amatller de Barcelona, no hemos localizado ninguna obra.

Respecto a su filiación estilística no cabe duda de que en ella se halla cierto influjo de Morales, pero creo que no hasta el extremo de considerarle del taller. Podría tratarse de un epígono del maestro, en cuanto al color y cierto dramatismo, conseguido a base de efecto de claroscuro, pero, desde luego, más contenido y matizado por la influencia de la pintura toledana de aquellos años, y por la catalana que pudo conocer, lo que no le resta singularidad a este artista literato de nuestra pintura del siglo XvI, del que esperamos sigan apareciendo nuevas obras, después de la aparición de este trabajo, que puedan configurar su trayectoria artística.

Hace algunos años tuve la ocasión de conocer en una colección privada de Lille (Francia), una tabla de la Magdalena (fig. 9), muy similar a la de Morales, que se conserva en el noviciado de los jesuitas, de Salamanca (fig. 10). Esta última fue reproducida por Bäcksbacka, como obra dudosa del maestro y procedente de la iglesia de San Marcos de la misma ciudad ${ }^{15}$. No cabe duda de que se trata de una de las obras de ejecución más delicada del maestro extremeño y, por ello, copiada literalmente en la composición de la tabla francesa, con las variantes de la presencia del tarro de perfume y el halo que adorna la cabeza.

Por la forma de plegar los paños, el tratamiento del cabello y el modelo de la santa, nos atrevemos a poner en relación la tabla de Lille, con el modelo de la Asunción de la Virgen (figs. 11-12), que se conserva en un salón de la Casa Antigua del Ayuntamiento de Trujillo (Cáceres), descrita por Mélida como de «excelente mano, tal vez florentina» ${ }^{16}$. Esta atribución a la escuela italiana es frecuente en los autores de fines del xIX y comienzos del xx cuando clasifican obras toledanas de Correa o sus seguidores, con el que sin duda, la Asunción, tiene mucho en común. El Exmo. Ayuntamiento de Trujillo ha tenido la bondad de facilitarme una nota transcrita del Libro de Actas del Concejo, con fecha de 1 de febrero de 1593, referente al autor de esta tabla: «Este día se trató de la imagen de pintura de Nuestra Señora de la Capilla de este Ayuntamiento y que el retrato que su merced el Corregidor tiene que ha fecho Pedro Mata, pintó esta de gran perfección, y es retrato sacado de la imagen de Nuestra Señora de la Mayor de Roma, que retrató el bienaventurado San Lucas a la Madre de Dios, y acordó que se faga la imagen al mismo retrato y convenciose a Rodrigo de Sanabria y a Don Diego de Vargas para que le fagan poner en la dicha capilla, lo que se convencio a los dichos y a cada uno de ellos para que lo concierten y por su orden se paguen y fagan». No hemos localizado el nombre de Pedro Mata en la monografía de Luis de Morales, de Solís Rodríguez; tampoco entre los pintores toledanos documentados de nuestra monografía, en prensa, La pintura toledana de la segunda mitad del siglo XVI, ni en diccionarios ni en ficheros de artistas, pero, es sabido no sólo de las vinculaciones entre Correa y Morales, en obras concretas, sino de la presencia de pintores toledanos en Extremadura en el siglo xvi. Ello hace viable el que el autor de estas tablas pueda ser un pintor de Toledo, que aún permanece anónimo, y que se desplazó desde la ciudad Imperial, a otros lugares próximos a la diócesis, recuérdese por ejemplo la presencia de Correa

${ }^{15}$ Loc. cit. nota 7, fig. 170. Cat. A40. $1,30 \times 0,87 \mathrm{~cm}$, dándole un paradero desconocido.

${ }^{16}$ R. Mélida, Catálogo Monumental de España. Provincia de Cáceres, pp. 375-377. 

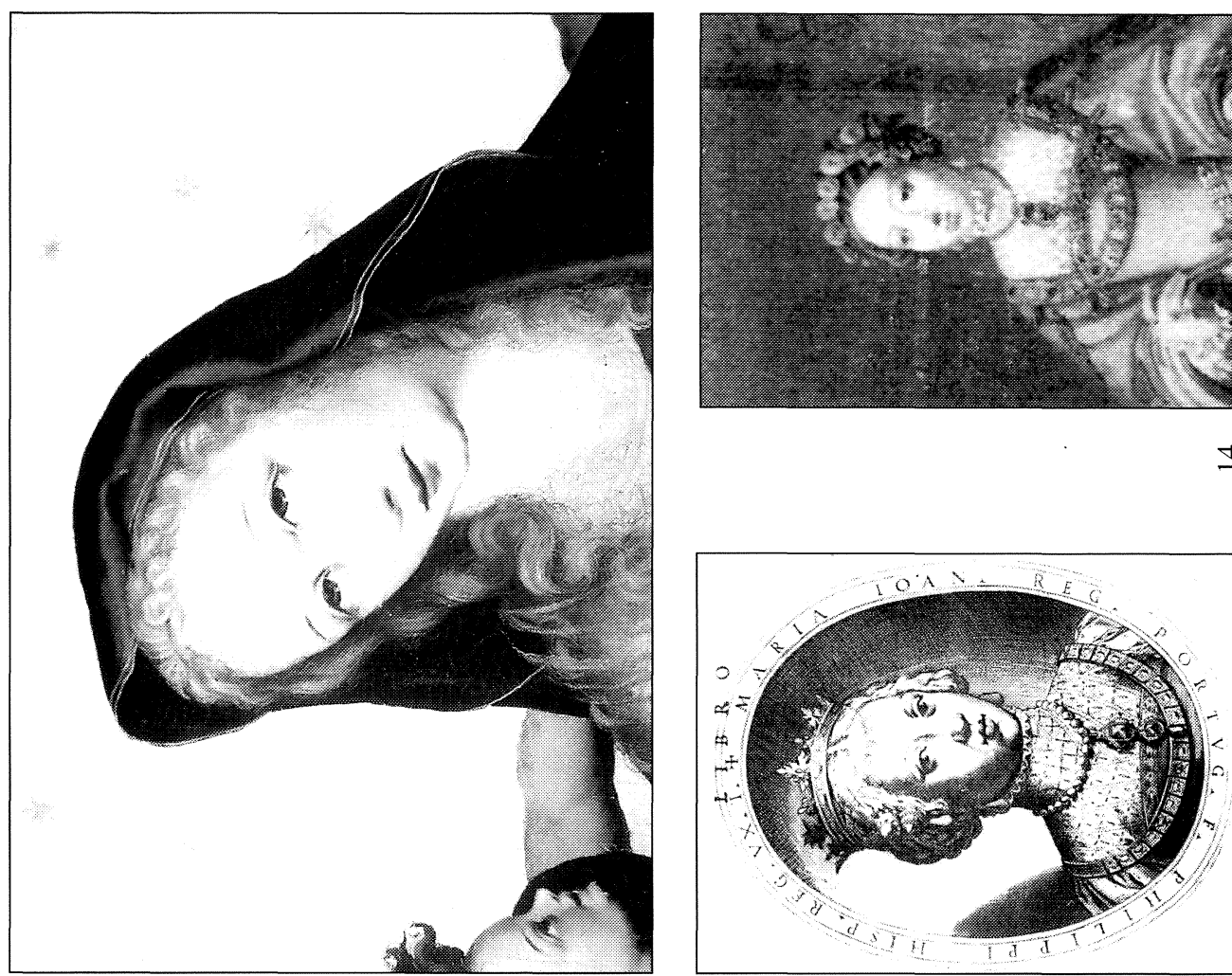

完
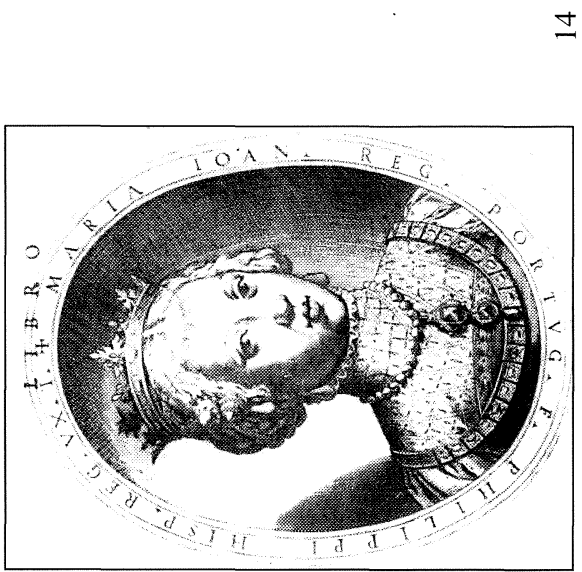

ํㅡㅇ

$\simeq$

$=$

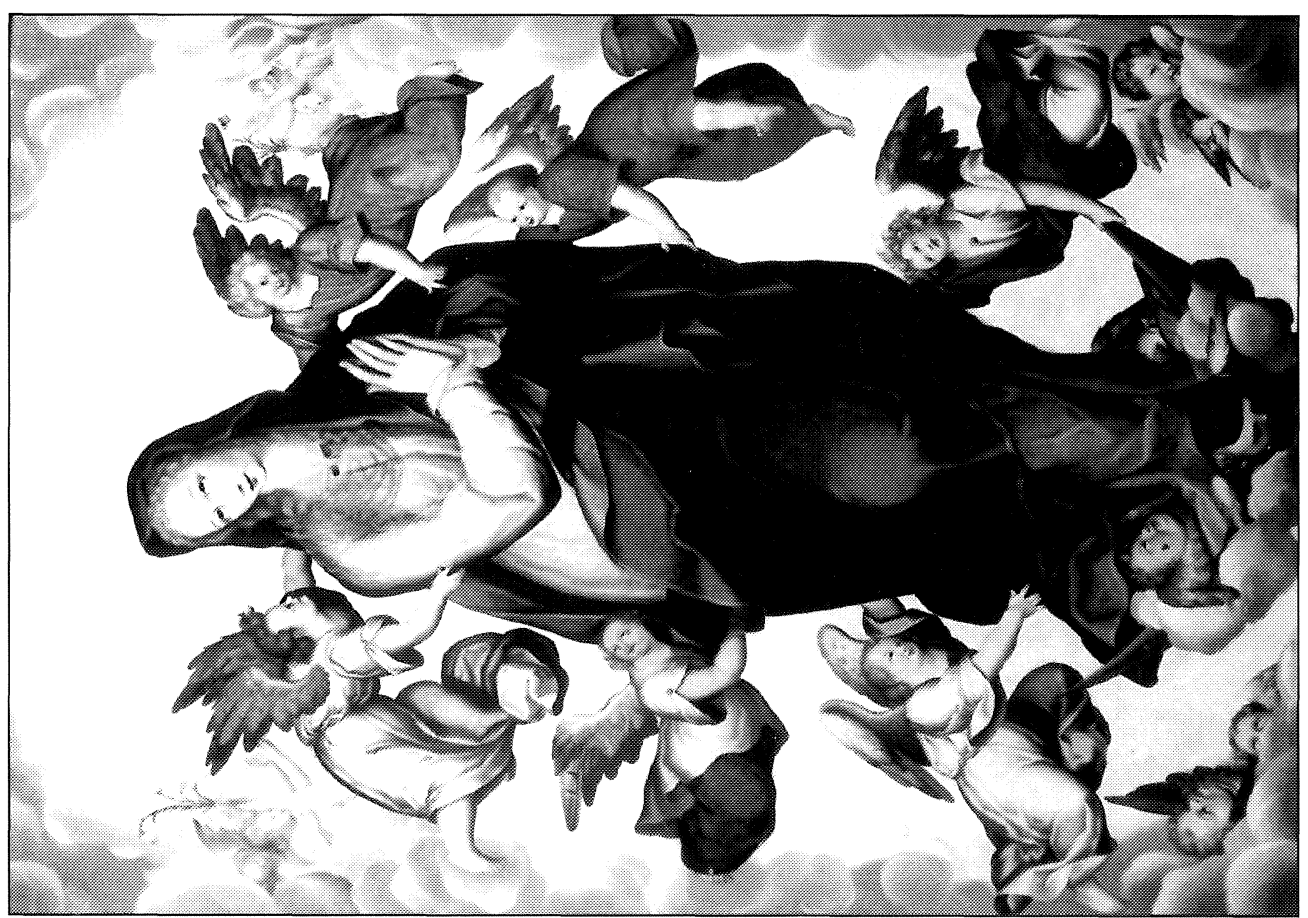

AEA, LXXVI, 2003, 303, pp. 301 a 329 
en Herrera del Duque (Badajoz) y Guadalupe, y de Cyaneus en Villar del Pedroso (Cáceres). Bien sea un pintor toledano o extremeño, de lo que no cabe duda es de que se trata de un artista de cierta calidad, vinculado al círculo de Morales y al que no es ajeno el ambiente pictórico toledano contemporáneo y, a propósito de ello queremos citar el nombre de fray Juan Moreno, autor de una cena en el convento toledano de San Clemente, y cuyo rostro de San Juan Evangelista es similar al de la Virgen de la Asunción.

No cabe duda de que la Magdalena de Lille debió salir de España bien durante las guerras napoleónicas o cuando la desamortización ${ }^{17}$.

Isabel Mateo Gómez Dpto. de Arte del C.S.I.C.

\section{LA HIEROGLYPHICA Y EL NACIMIENTO DE VENUS}

De la pintura

Sin duda a Botticelli se le debe el honor de ser el primero en pintar cuadros mitológicos monumentales que en tamaño competían con el arte religioso de la época. Entre sus argumentos, los más afamados vienen a ser las dos pinturas (hacia 1478) hoy custodiadas en los Uffizi y que conocemos como La Primavera y el Nacimiento de Venus, fábulas que proceden muy probablemente de la Villa di Castello de la que era propietario Lorenzo de Pierfrancesco, primo de Lorenzo de Médici y mecenas del maestro pintor. Las dos pinturas, como analizan importantes historiadores como Gombrich y Panofsky parecen responder a un concreto programa argumental de claro sentido platónico y que explican la idea del Amor a través de la Venus Humanitas y la Celestis, es decir, el sentimiento humano y el contemplativo, comportamientos generados por Dios y por lo tanto, buenos en sí mismos.

De la placenta marina como gestación del espíritu: El Nacimiento de Venus (fig.1).

El mar tuvo una importancia extraordinaria como medio de vida, las mitologías lo entendieron como algo más, como placenta de la que surgió la diosa más perfecta de cuantas se dieron cita en el Olimpo: Venus. Así se narra en la fábula clásica, pues leyendo a Hesíodo en su Teogonía sabemos que Urano (Cielo) se unió con Gea (Tierra), y temiendo el poder de los hijos que ambos tuvieron, los asesinaba estrellándolos contra la propia madre o tierra. Gea pidió a sus hijos venganza, venganza que realizó el pequeño de ellos, llamado Cronos o Saturno. Así nos lo cuenta el griego:

Madre, en verdad te prometo llevaré a cabo esta venganza. Efectivamente, ya no tengo respeto a nuestro padre, porque él fue quien primero meditó un designio cruel.

Habló así, y la gran Gea se regocijó en su corazón. Y lo escondió en una emboscada, y le puso en la mano la hoz de dientes cortantes, y le confió todo su designio. Y llegó el gran Urano, trayendo la noche, y se tendió sobre Gea por entero y con todas sus partes, lleno de un deseo de amor. Y fuera de la emboscada, su hijo le cogió la mano izquierda y con la derecha

\footnotetext{
${ }^{17}$ No queremos sustraernos a la tentación de encontrar cierto parecido entre el rostro de la Magdalena de Lille con el de María de Portugal, primera esposa de Felipe II, quien pasa por Badajoz en 1543, camino de Salamanca, para contraer matrimonio con el monarca. (figs. 13-14).
}

AEA, LXXVI, 2003, 303, pp. 301 a 329 